\title{
Discusiones doctrinales y problemas de traducción. La representación de la Santísima Trinidad, la virgen María y los ángeles en La fazienda de Ultramar
}

\author{
Doctrinal disputes and translation problems. The depiction of the Holy Trinity, \\ the Virgin Mary and angels in La fazienda de Ultramar
}

\author{
Melisa Laura Marti \\ melisa_marti@yahoo.com \\ Seminario de Edición y Crítica Textual. Instituto de \\ Investigaciones Bibliográficas y Crítica Textual. \\ Universidad de Buenos Aires / CONICET, \\ Argentina
}

Recepción: 30 Octubre 2020

Aprobación: 24 Abril 2021

Publicación: 03 Mayo 2021

Cita sugerida: Marti, M. L. (2021). Discusiones doctrinales y problemas de traducción. La representación de la Santísima Trinidad, la virgen María y los ángeles en La fazienda de Ultramar. Olivar, 21(33), e095. https://doi.org/10.24215/18524478e095
Resumen: La fazienda de Ultramar es un texto del siglo XIII que traduce la Biblia a la manera de los itinerarios o guías de peregrinos medievales: en él, la selección de pasajes de la Escritura está motivada por la geografía de Tierra Santa, que orienta el recorrido por los relatos bíblicos. El objetivo de este trabajo será profundizar en las operaciones discursivas que diferencian a La fazienda de Ultramar de sus fuentes y de otros romanceamientos, y que reflejan las dificultades que enfrentaban los primeros traductores de la Biblia a las lenguas vernáculas. Nos centraremos específicamente en los aspectos que se vinculan con los debates de índole doctrinal y las discusiones teológicas propias del momento de redacción de la obra. Por ello, analizaremos la representación de la Santísima Trinidad, la Virgen María y los ángeles, augurando que nos permitirá conocer el sistema cultural en que se ubicaba el autor y su modo de trabajo en tanto traductor.

Palabras clave: Prosa castellana, Itinerario, Biblia romanceada, Siglo XIII.

Abstract: La fazienda de Ultramar is a thirteenth-century
translation of the Bible that replicates the structure of the
medieval itineraries or pilgrim narratives: the selection of
passages from Scripture is motivated by the geography of the
Holy Land, which guides the way through biblical stories. This
study aims to deepen into the discursive operations that separate
La fazienda de Ultramar from its sources and other translations
of the Bible, and which reflect the difficulties and issues met
by the first translators of the Bible into vernacular languages.
We will specifically reflect upon those which are connected
with doctrinal debates and theological discussions relevant at the
time of the composition of the work. Therefore, we will analyse
the representation of the Holy Trinity, the Virgin Mary and
angels, hoping it will allow us to comprehend the cultural system
its author inhabited and the techniques he incorporated as a
translator.

Keywords: Castilian prose, Itinerary, Vernacular Bible, Thirteenth Century. 
El estudio de las primeras traducciones de la Biblia a la lengua castellana es tan problemático como revelador: el acercamiento a estos textos y su análisis comparativo nos permiten conocer cómo fueron los primeros ensayos para convertir el castellano en vehículo de las palabras sagradas, y explorar este proceso no sólo es relevante para el conocimiento lingüístico, sino también para la historia de la doctrina cristiana, su reformulación y su aceptación en un ámbito histórico, intelectual y cultural determinado.

Esta problemática se ve claramente representada en La fazienda de Ultramar, un texto del primer tercio del siglo XIII que traduce la Biblia a la manera de los itinerarios o guías de peregrinos medievales: en él, la selección de pasajes de la Escritura está motivada por la geografía de Tierra Santa, que orienta el recorrido por los relatos bíblicos. En consecuencia, se omiten libros completos de la Biblia, se reordenan sus episodios y se superponen fragmentos del Antiguo y el Nuevo Testamento en un mismo punto geográfico, lo que genera múltiples sentidos a partir de la recuperación de su conexión espacial. A su vez, el análisis de su entramado textual revela que la Biblia -hebrea y latina- no fue la única fuente aprovechada por el redactor de La fazienda, ya que encontramos fragmentos del discurso litúrgico, de textos apócrifos e incluso de autores tan ajenos a la doctrina cristiana como Ovidio.

La complejidad del proceso de traducción, hasta aquí ilustrado de forma sintética, dio lugar a una serie de problemas conceptuales que reflejan debates doctrinales y discusiones teológicas propias del momento de redacción de la obra y que ponen de manifiesto las dificultades que enfrentaron las primeras generaciones de traductores de la Biblia a las lenguas vernáculas. Es por ello que el objetivo de este trabajo será profundizar en las operaciones discursivas que diferencian a La fazienda de sus fuentes y de otros romanceamientos y que se vinculan con los debates de índole doctrinal en los que se involucraron los primeros traductores de la Biblia al castellano. En esta oportunidad, nos centraremos en el análisis de la representación de la Santísima Trinidad, la Virgen María y los ángeles para describir el sistema cultural en que se ubicaba el autor y su modo de trabajo en tanto traductor. Nos ocuparemos de los pasajes que muestran una desviación con respecto al canon bíblico para recuperar la hibridez identitaria de La fazienda y explorar la multiplicidad de fuentes textuales y tradiciones discursivas que están insertas en ella.

La fazienda de Ultramar es un claro ejemplo de cómo la creación literaria medieval dependía de la traducción de materiales diversos y privilegiaba la integración de distintas tradiciones para comunicar la experiencia de un mundo heteróclito. En este sentido, el proceso de traducción debe entenderse como un fenómeno históricamente determinado, como "la producción de un texto adecuado al contexto de destino" (Delpy, Funes y Zubillaga, 2009, pp. 14-15), y no como la transposición de conceptos entre lenguas. Es por ello que las elecciones léxicas en un contexto fuertemente condicionado por la doctrina religiosa son profundamente reveladoras acerca del contexto de producción y las condiciones de circulación de un texto como el que nos ocupa. El proyecto de su autor, como podrá verse, trascendía el de la guía para peregrinos y descripción de la geografía mediooriental para insertarse en los debates acerca de la doctrina cristiana y su transmisión por medio de distintas tradiciones discursivas. La indagación del autor acerca del significado de los nombres va más allá del estudio de los topónimos y sus equivalencias en las distintas lenguas, como proponía en el comienzo del códice, y se expande hacia términos de por sí problemáticos para los estudios teológicos. Así lo advirtió Fernando Gómez Redondo cuando analizó la búsqueda lingüística del autor de $L a$ fazienda y señaló su proximidad con la amplificación o el comentario propios de las glosas escolásticas; Gómez Redondo se refirió a "un proceso de desvelamiento de significados casi herméticos, cercanos a la cábala, ya que, de hecho, se va a profundizar en el valor del nombre como portador de carga semántica" (1998, p. 115), lo que resulta perfectamente adecuado a la luz del estudio de los pasajes de los que nos ocuparemos. 


\section{PARticipación ANGÉlica}

Los ángeles aparecen en numerosas ocasiones en La fazienda de Ultramar, en varias de ellas participando de los hechos de una forma muy diferente a la que podemos encontrar en la Biblia.

La primera de estas ocurrencias la encontramos en ocasión de la muerte de Moisés y la mención de su sepultura en Deuteronomio 34:6, donde el autor de La fazienda se distancia ostensiblemente de la fuente bíblica de una forma que los traductores que lo sucedieron no osaron emular:

Subió Moisén en los planos de Moab sobr'el mont de Nebo, a cabo del otero de Faga, a vista de Jericó. Amostrol' Nuestro Señor toda la tierra de Judá troa la mar postremera, el darom e la plana del campo de Jericó en la cibdad de los palmares, troa Segor. Dixo el Nuestro Señor a él: "Esta es la tierra por que juré a Abraam e a Isaac e Jacob, e dix 'A to liñaje la daré'. Verasla con tos ojos”. En ella murió Moisén, siervo del Criador, en tierra de Moab, por mandado de Dios. Soterráronlo los ángeles en el val en tierra de Moab contra Belfegor, e non sopo omne so sepulcro troa'l día de oy. Moisés era en edad de CXX años quando murió. No's' escalfaron sos ojos ni non se fusó su color e no 's' le metieron sos dientes ${ }^{1}$. (f. $\left.27 \mathrm{r}\right)^{2}$

Ni la Biblia hebrea, ni la Vulgata, ni las traducciones medievales aluden a los ángeles en este pasaje. ${ }^{3}$ De hecho, la forma verbal hebrea equivale a "fue sepultado" (lo que podría interpretarse como que los responsables fueron los hombres) tanto como a "él lo sepultó" (esta última traducción es la que coincide con la forma latina; en la Septuaginta, por otra parte, se traduce como "ellos lo sepultaron”). Es así que en la General estoria se resuelve la forma impersonal del verbo latino y hebreo con "soterrolo Él mismo" (Solalinde, 1930, p. 747), mientras que las traducciones contemporáneas mantienen, con variantes, "enterrolo" o "soterrolo", sin dar especificaciones, aunque se sobreentiende que fue Dios mismo. Esta falta de precisión en las fuentes supuso varios interrogantes que los traductores intentaron resolver: si lo enterraron los hombres, ¿̨por qué

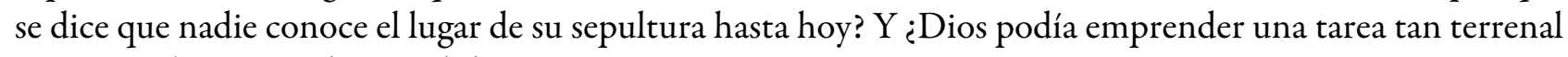
como sepultar a uno de sus súbditos?

Existían muchos relatos acerca de la muerte de Moisés y su sepultura. Ya en el siglo I, en su Vida de Moisés

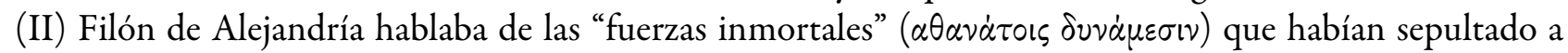
Moisés en ausencia de los hombres (Cohn, 1902, p. 268), con lo que quizá estuviera respondiendo a la necesidad de explicar el hecho de que "ningún hombre" conociera el sitio de la sepultura y el destino de los restos de Moisés; por esta razón, nació una tradición entre comentadores y escolares quienes llenaron el vacío de las formas verbales ambiguas con la idea de un poder superior que se ocupó de la sepultura de Moisés y que posteriormente se encargaría de su ascenso al cielo.

Por otra parte, es posible que esta intervención de los ángeles en representación de Dios dependa de un pasaje del Nuevo Testamento, contenido en la Epistola de Judas: "Pero cuando el arcángel Miguel contendía con el diablo, disputando con él por el cuerpo de Moisés, no se atrevió a proferir juicio de maldición contra él, sino que dijo: El Señor te reprenda" (Jud.1:9). ${ }^{4}$ El texto, que presenta similitudes con el apócrifo El testamento de Moisés (o La asunción de Moisés), ${ }^{5}$ alude a la disputa entre el arcángel y el demonio por Moisés, y había sido retomado por teólogos del cristianismo temprano, como Orígenes, en el marco de discusiones acerca de los poderes opuestos y el origen del mal. La cuestión que se debatía entre el arcángel y el demonio era si Moisés debía o no ascender al cielo por haber matado al egipcio en Éxodo 2:12, lo que servía para explicar el emplazamiento secreto de su tumba.

Más allá de estos posibles hipotextos, la tradición acerca del rol de los ángeles en el entierro de Moisés estaba ampliamente extendida por los pueblos de raíces judaicas, como lo demuestra la leyenda de los Beta Israel, la comunidad judía de Etiopía, quienes recitaban la historia de la muerte de Moisés como parte de sus ritos fúnebres. En ella se cuenta que Moisés le pide unas horas al Ángel de la Muerte para despedirse de sus seres queridos y, por haberse mostrado temeroso frente a la muerte, es consolado por Dios, quien le muestra que hasta un gusano que se alimenta de pasto en el lecho del Mar Rojo es objeto de su protección. Luego se encuentra con tres hombres -los ángeles- que cavaban una tumba, quienes le piden que se acueste en ella 
para ver si es lo suficientemente grande. Allí se encuentra con el Ángel de la Muerte, que pone fin a su vida para que los ángeles lo sepulten. El relato, que podría basarse en fuentes árabes, ${ }^{6}$ pone en evidencia la amplia circulación de esta versión de los hechos.

En efecto, la narración de la muerte de Moisés presenta muchas similitudes con la leyenda musulmana recogida por Gustav Weil, en la que Moisés ve cuatro hombres cavando una tumba, los asiste para verificar que el tamaño era correcto y es abordado por el Ángel de la Muerte, profeta de Alá: "at that instant his noble soul rose through his nostrils to heaven. But his body remained in this grave, which no one knew save Gabriel, Michael, Israfil, and Azrail, who had dug it, and whom Moses had taken for men" (Weil, 1846, p. 143). La presencia de esta narración en la tradición oral árabe (tomada probablemente de fuentes orales hebreas) es una evidencia de lo relevante que era la figura de Moisés para las diversas tradiciones que construyeron la historia de su vida con estas variantes tan llamativas.

Por otra parte, el fragmento del texto árabe, además de remarcar que nadie excepto los ángeles conocía el sitio de la tumba de Moisés, nos remite a otro episodio en el que Abraham se encuentra con un grupo de ángeles y tampoco los reconoce, que se relata en Génesis 18. Nos ocuparemos de esto en el siguiente apartado.

Encontramos otra novedosa intervención angélica en ocasión de la traducción de Números, que presenta algunas variaciones en la historia de Balac y Balaam (Nú.22:9-20). En ella, se cuenta que el rey de Moab temía la cercanía del pueblo de Israel y, por medio de unos mensajeros, le pide al profeta Balaam que lo maldiga. Balaam, luego de consultarlo con Dios, se niega a hacerlo tras conocer que se trata del pueblo elegido. En La fazienda, sin embargo, leemos:

Moviéronse fijos de Israel e posaron en el plano de Moab, a parte de flum Jordán e de Jhericó. Oyolo Balaac, fijo de Cipor, que era rey de Moab, e ovo grant miedo e pesol' mucho. E dixo a los viejos de Madián: “Agora gastará aquella gent nuestra tierra cumo gasta el buey la yerba del canpo". Embió mensajeros a Balaam, fil de Beor e dixo: "El pueblo que salió de Egipto e cubrió toda la color de la tierra e es contra mí, es más fuerte de mí. Anda agora e maldizle. Quiçab podrelo esterrar, ca sé que el que bendizes, bendicho es; el que maldizes, maldito es”. E vinieron estos mandaderos a Balaam e aduxiéronle present e contáronle estas palabras. E dixo Balaam: "Set aquí esta noch e tornarvos he mandado de lo que fablará mio Señor", e fizieron assí. Vio ángel del Nuestro Señor a Balaam e díxol’: “¿Quí son estos barones que vinieron a tu casa?”. E contógelo todo Balaam. E dixo el ángel: "No vayas con ellos e no maldigas el pueblo que es bendicho". (f. 24r)

Encontramos aquí el rol del ángel como intermediario de Dios, a diferencia de lo que leemos en la Biblia. En ella, Balaam invita a los hombres a permanecer con él hasta que reciba el consejo del Señor, quien se le aparece en la noche y le recomienda no ir con los hombres de Balac, ya que no debía maldecir al pueblo bendito.

Sucede lo mismo con la segunda embajada de los nobles enviados por Balac, quienes insisten a Balaam para que los acompañe a ver a su señor. Balaam vuelve a negarse y recibe una vez más la visita del ángel, que lo pone a prueba autorizándolo a partir con los embajadores de Balac: "Vino el ángel del Nuestro Señor a Balaam de noch e díxol': "Si por clamarte vinieron estos barones, liévat' e ve con ellos. Mas lo que yo te fablo, eso faz" (f. 24r-v). En este caso, como en los anteriores, la Biblia se refiere a Dios mismo como interlocutor de

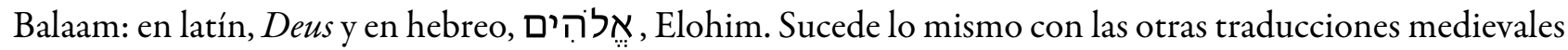
de la Biblia, con excepción de la Biblia EscorialE19 (de finales del siglo XIII), en la que también se habla del ángel de Dios. A continuación, Balaam parte al encuentro con Balac en su asno y se encuentra con un ángel que le impide el paso con su espada desenvainada. Al principio, sólo el asno puede verlo y se niega a avanzar; pero una vez que Dios abre los ojos de Balaam se disculpa frente al ángel y se compromete a comunicarle a Balac lo que el ángel le diga (Nú. 22:21-35).

Finalmente, en el capítulo siguiente es el ángel quien habla a través de Balaam cuando este expone profecías frente a Balac y sus hombres (Nú.23:4-16). En este caso y en el que sigue unas líneas más abajo, La fazienda de Ultramar coincide con la Biblia de Arragel (ca. 1425). Así, luego de que Balaam ordenara a Balac que hiciera sacrificios, anuncia que se encontrará con Dios para que le detalle cómo debe proceder; pero, una vez más, se encuentra con su ángel, quien bendice a Israel a través de Balaam, para desconcierto y furia de Balac (Nú.23:1-12). Unas líneas más adelante, en ocasión de la segunda profecía de Balaam, el procedimiento es 
el mismo. Balaam anuncia que se encontrará con su Señor, pero es el ángel quien le ordena que vuelva con Balac para transmitirle su palabra: "Dixo Balaam: 'Está aquí e encontrarme é con mio Señor'. Fabló el ángel e tornos' a Balaac e díxol': 'Lieva, Balaac, e oy e ascucha mis palabras, fil de Cipor”' (f. 25r).

Como podemos ver en estos fragmentos, en La fazienda hay una tendencia a otorgarles una mayor participación a los ángeles en pasajes en los que su intervención parece intercambiable con la del Dios al que representaban, y se enfatiza que en ellos opera la manifestación divina. Sobre ello había escrito San Agustín en Cuestiones sobre los Números, donde reflexiona acerca del rol del ángel:

Dice la Escritura que Dios encolerizado dijo: Y el ángel de Dios se levantó, sin decir que Dios, irritado, envió al ángel; pero en cierto modo simbolizó en el ángel a Dios irritado, pues la verdad y la justicia de Dios hicieron que él se irritara. (García de la Fuente, s/f, párr. 49)

Por otra parte, en el relato de Balaam y Balac, posiblemente el autor de La fazienda haya buscado darle una mayor coherencia narrativa a la historia para explicar la motivación del ángel en su encuentro con Balaam y su asno, ya que aquí es el ángel quien le pide que reproduzca sus palabras frente a Balac. En esto, La fazienda se diferencia de las otras traducciones medievales mencionadas, que son menos consistentes y sistemáticas en su interpretación de la participación angélica. Esta posibilidad, por otra parte, tiene una significación mucho más profunda en el pasaje que analizaremos a continuación.

\section{LA TRINIDAD ANGÉLICA}

La participación de los ángeles tiene una significación especial en otro pasaje que fue objeto de disputas doctrinales. Se trata del episodio en que Abraham ve tres hombres en el camino, que el autor de La fazienda incluye inmediatamente después de iniciar su itinerario en Hebrón y de detenerse en Mamré. El fragmento está destacado por la rúbrica que anuncia "Aquí fue demostrado a Abraam trinidat, vio tres barones y el uno adoró” (f. 1v). Con ello alude a Génesis 18:1-2, donde Dios aparece ante Abraham en el encinar de Mamré bajo la forma de tres hombres: "Vio Abraam III barones que passavan por la carrera. A todos III nonbró por uno e díxoles: 'Señores, Adonay'. Por esto diz que tres vio él, uno adoró” (f. 1v). Y, más abajo: "estava Abraam so la enzina en Manbre e vio III barones que pasavan por la carrera e corrió en so encuentro e omillós'les III vezes troa tierra" (f. 2 r).

La frase "tres vio él, uno adoró", si bien debe entenderse en el contexto de los versículos ya mencionados, no aparece en la Biblia, sino que era parte de un responsorio del domingo de Quincuagésima: "Dum staret Abraham ad ilicem Mambre vidit tres viros descendentes per viam tres vidit et unum adoravit", 8 que aparece citado parcialmente justo antes de la rúbrica mencionada. ${ }^{9}$ Cabe destacar que las citas del repertorio litúrgico están diseminadas a lo largo del texto, y representan un alto porcentaje de las frases trascriptas en latín.

En uno de los primeros trabajos que mencionan a La fazienda de Ultramar, Diego Catalán ya había analizado las citas de textos litúrgicos como prácticas comunes a mediados de los siglos XIII y XIV, y aludió a este pasaje como ejemplo de la "práctica viciosa" de las citas en falso (1965, p. 313). De esta forma, Catalán se refería a la preferencia de los autores medievales por aquellas "expresiones y pasajes repetidos en la liturgia, los himnos, los evangelios dominicales, las homilías, que fácilmente quedaban prendidos en memorias acostumbradas a la adquisición de conocimientos por vía auditiva" (íbid., p. 314). Como podemos ver en la cita en cuestión, esta "contaminación" de fuentes, en la que la memoria auditiva influía sobre el modo de transmisión de un pasaje bíblico, podía traer aparejados otros problemas que van más allá de la cita en latín ligeramente modificada, como las que encontramos con frecuencia en otros lugares del texto.

Vemos, entonces, que en La fazienda de Ultramar en ocasiones se insertan frases que no pertenecen en absoluto al Antiguo Testamento, como sucede a propósito del encuentro de Abraham con los tres hombres. Era frecuente adjudicar a Abraham las palabras "tres vi y uno adoré, ${ }^{10}$ como denunciaban los teólogos medievales referidos por Catalán, para explicar el hecho de que Abraham se hubiera dirigido a uno solo 
de estos hombres en el diálogo tal como aparece en la Biblia. Las soluciones que propusieron los exégetas medievales fueron diversas, y su repercusión alcanzó a otras tradiciones discursivas.

En efecto, la polémica en torno a la prefiguración de la Trinidad en el Antiguo Testamento ya se había desarrollado en la tradición patrística a partir del siglo IV, y había sido objeto de una exposición de Agustín de Hipona en su Réplica a Maximino, obispo arriano, como refutación a la tesis de que aun antes de la encarnación, Jesucristo se hizo visible a los hombres. Agustín desglosa el capítulo contraponiéndolo al encuentro de Lot con los ángeles (Gn. 19) para demostrar cómo este y Abraham reconocieron a Dios en los ángeles: "Abrahán vio tres, y adoró a uno solo, de quien no quiso ser olvidado, y recibió de uno solo la respuesta de la divinidad. Ni pensó que los otros dos de ellos eran dioses, sino un solo Dios en todos" (Ozaeta y Madrid, s/f, párr. 26.7). Además de establecer que se trataba de una manifestación de los ángeles, Agustín concluye que Dios pudo ser visto por los hombres a través de sus representantes, y refuta que Abraham haya visto al hijo de Dios (solo o en compañía de dos ángeles). Por lo tanto, en este episodio, Dios "está más significado en figuras que mostrado en la realidad" (ibid., 26.10).

Si bien el alcance del texto de San Agustín es evidente, puesto que allí se incluye la frase "tres vidit et unum adoravit" tal como la encontramos en La fazienda y en el oficio litúrgico, la reflexión en torno a este tópico ya había aparecido en San Ambrosio, como explica Bartelink en su artículo acerca de esta polémica: para Ambrosio, en el que resuena la influencia de Filón de Alejandría y Orígenes, la escena constituye "un symbole de l'unité de Dieu qui se manifeste en trois personnes, de sorte qu'il est en effet amené à y voir une préfiguration du mystère de la Trinité" (1984, p. 24).

Es evidente que en más de un ámbito primó la interpretación tipológica, puesto que no sólo encontramos su inserción en el discurso litúrgico, sino también en otros itinerarios bíblicos, tales como Descriptio de Locis Sanctis de Rorgo Fretellus (ca. 1140), en la que se cita textualmente a Ambrosio y Agustín al referirse a la encina de Mamré, "sub qua quidem tres angelos vidit et unum adoravit" (Boeren, 1980, p. 10). ${ }^{11}$ La cita se había extendido incluso a otras lenguas vernáculas, como demuestra la Crónica de Ernoul (ca. 1231): “Un en vit, \& iij en aoura; li iij eftoient en un; \& li uns eftoit en iij; \& tout en une perfonne" (Michelant y Raynaud, 1882, p. 66); de manera similar, en Les pelerinaiges por aler en Iherusalem (ca. 1231) encontramos: "Emprès d'iqui fe demonftra Noftre Sire en forme de la Trinité à faint Abraham, \& faint Abraham vit .iij. perfonnes, fi en aoura une" (ibid., p. 99); y en La Sainte cité de Iherusalem, les Saints Lieux \& le pelerinage de la Terre, una interpolación a la traducción francesa de la Historia Hierosolymitana de Guillermo de Tiro: "Prèz d'illeuc aparut Noftre Sirez à Abraham en fa Trinité. Car il en vit troiz, \& un en aoura” (íbid., p. 170). ${ }^{12}$ Como puede verse en estos extractos, los itinerarios franceses son mucho más explícitos a la hora de formular el concepto que el texto hispánico y el latino abordan con una frase eufemística.

Por otra parte, no es este el único pasaje de La fazienda en que se destaca una motivación tipológica: hacia el final hay una veintena de profecías con las que su autor intentaba recomponer los vínculos entre el Antiguo Testamento y el Nuevo. ${ }^{13}$ Se trata de una serie de citas ya aparecidas a lo largo del texto que el autor incorpora al final para destacarlas por ser de gran importancia para el cristianismo, ya que en ellas hay alusiones a la venida de Cristo.

Ciertamente, el autor de La fazienda aprovechó el recurso de la tipología como una herramienta compositiva y de interpretación con el objetivo de "reforzar la estructura, iluminar la organización conceptual y crear sutiles correspondencias temáticas entre las diferentes partes de una misma obra" (Gerli, 1985, p. 8). Como ya es sabido, a través de esta herramienta se establecían conexiones entre acontecimientos y personajes del Antiguo Testamento y del Nuevo, con el fin de reinterpretar el primero desde una perspectiva cristiana, por lo que se entendía que sus imágenes anticipaban lo relatado en el segundo. ${ }^{14}$ En este marco conceptual, la expulsión de Adán del Paraíso se interpretaba como una repetición invertida del advenimiento de Cristo, que marca la salvación del hombre.

No parece casual que el itinerario de La fazienda se inicie en Hebrón, con el relato de la Creación, y que en los dos últimos folios (luego de haber retornado al punto geográfico de partida) encontremos profecías 
de redención. Se cumple, entonces, el esquema de elaboración figurativa que analiza Gerli, por el que los acontecimientos del Antiguo Testamento se repiten de forma invertida en el Nuevo. Por lo tanto, el itinerario volcado en La fazienda no es sólo físico o terrenal, lo que está expresado en la secuencia de hitos geográficos; sino también simbólico, y pone de manifiesto un viaje -colectivo, universal- cuyo punto de partida es la pérdida del Paraíso y la caída en el pecado, y el de llegada es la promesa de salvación y de recuperación de ese Paraíso.

De este modo, el hecho de que la trama narrativa de La fazienda de Ultramar esté supeditada al espacio y no a la estructura de los libros de la Biblia cobra otra relevancia, y la resistencia que encontramos en ella a respetar la estructura canónica se resignifica. Es claro que la insistencia sobre el carácter tipológico que se les intenta conferir a los avatares de Moisés, Abraham, Jacob o José se vincula estrechamente con la superposición de historias en los distintos puntos geográficos, con la que se difumina el eje temporal y se crea la ilusión de una sincronía, en la que cada hecho narrado se encadena y se ilumina a la luz de otros.

\section{LA PROFECÍA DE LA MANCEBA}

Además del fragmento dedicado a la asunción de la Virgen María, probablemente tomado de un texto apócrifo, La fazienda incluye otro pasaje particularmente llamativo desde el punto de vista doctrinal en relación con el culto mariano, como ya fue señalado por Emily Francomano (2011, pp. 315-337). Se trata de la profecía de Isaías 7:14, en la que el profeta anuncia a Acaz que Dios protegerá a su pueblo, y tendrá como señal el nacimiento de un niño, Emmanuel:

Dixo [Isaías]: “Oít agora, casado de David: ¡sí poco a vós es de ensañar varones, ca vós ensañades al Mio Dios? Por esso dará a vós es' Señor señal contra judíos. E la manceba concibrá e parrá fijo e clamará so nonbre Emanuel, ço es 'Dios con nós'. Manteca e miel conbrá por aborrecer e saber el mal e esleer el bien, e antes que sepa el mancebo aborrecer el mal e esleer el bien, será la tierra dexada en que tú estás estreito delant los II reyes”. (f. 57r) $)^{15}$

Como puede verse, el autor de La fazienda opta por utilizar el vocablo manceba para completar la profecía,

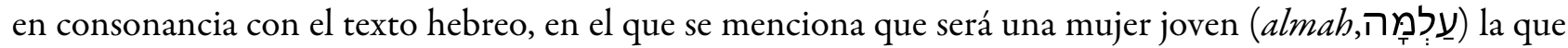
conciba al hijo de Dios. Por el contrario, tanto la Septuaginta (con el vocablo griego $\pi \alpha p \theta$ évos, parthénos, virgen) como el texto latino (virgo) aluden a una virgen en este contexto. Por esta razón, se trata de un pasaje clave para comprender el manejo de las fuentes por parte del autor de la obra: dado que La fazienda en las dos oportunidades traduce el pasaje haciendo mención de una manceba, podemos inferir que su redactor estaba trabajando sobre la base del texto hebreo, y que las citas en latín servían para ampliarla.

En su artículo sobre las traducciones castellanas de la Biblia, Francomano se encarga de señalar estas elecciones léxicas para nada inocentes en cada una de las traducciones al castellano de la Biblia y se pregunta:

What would a Christian reader, cleric or not, have seen in the use of alma or mançeba in the translation of a passage of central importance to the Christian typological relationship between the Old Testament with the New? A Christian polemicist may have found the translation useful for substantiating the accusation of Jewish tampering with the messianic prophecies of the original Hebraica veritas. On the other hand, this passage was also cited by Jews as proof of Jerome's mistranslation of Scripture when he returned to the Hebrew texts to create the Vulgate. (2011, p. 330)

En efecto, la elección de un término por otro marca un punto crítico de los problemas de traducción al que se enfrentaba el autor en su rol de compilador de fuentes y materiales textuales diversos. Por otra parte, la autora sugiere que las traducciones de la Biblia que incurren en esta transgresión doctrinal, que serían objeto de persecución inquisitorial, estarían destinadas a un público judío o de judíos conversos. Sin embargo, la inclusión en La fazienda del Libro de Judity los dos libros de Macabeos, aceptados como parte del canon bíblico por el cristianismo pero no por el judaísmo, nos inclina a pensar en una apertura a un público heterogéneo, y es una muestra del sincretismo cultural, filosófico y doctrinal que caracteriza a La fazienda, que se extiende incluso a la narrativa mitológica al incluir el microrrelato de Píramo y Tisbe. 
Como Francomano se encarga de remarcar, la frase tiene su eco en el Nuevo Testamento en ocasión del anuncio del ángel a José acerca de la naturaleza divina del embarazo de María, por lo que la resonancia tipológica tenía un peso mayor: “Todo esto aconteció para que se cumpliese lo dicho por el Señor por medio del profeta, cuando dijo: 'He aquí, una virgen concebirá y dará a luz un hijo, y llamarás su nombre Emanuel, que traducido es: Dios con nosotros"” (Mt. 1:23). ${ }^{16}$

Por este motivo, y por la evidencia que encontraban en otros pasajes bíblicos, los exégetas cristianos procuraron reconciliar estas variantes y asimilar sus significados. Así, Orígenes plantea en Contra Celso que almah necesariamente implicaba que la joven fuera virgen, porque de otra forma no podría ser considerada una señal:

¿Qué clase de signo sería, por lo tanto, aquel (que una mujer joven que no era virgen diera a luz a un niño)? Y ¿cuál de las dos sería más apropiada como madre de Emmanuel (es decir, "Dios con nosotros")? ¿Una mujer que tuvo relaciones con un hombre, y que concibió a la manera de las mujeres, o una que aún es una pura y sagrada virgen? Ciertamente, es propio solamente de esta última producir un ser de cuyo nacimiento se dice "Dios con nosotros". (Roberts-Donaldson, 1885:14) ${ }^{17}$

Como señalé más arriba, que el compilador de la obra optara por esta traducción es un indicio de que estaba consultando el texto hebreo, lo que fortalece la hipótesis acerca de la fuente textual principal de La fazienda. Efectivamente, el estudio lingüístico de la obra y el análisis de la doctrina que en ella se deja entrever me han conducido a concordar con la hipótesis de que el autor privilegiaba esta fuente sobre la latina, sin que esto signifique que no la consultaba, como puede comprobarse a partir del estudio de los topónimos que el autor recogió en sus distintas variantes lingüísticas. Sin embargo, el hecho de que el término virgen no aparezca en ningún otro contexto en La fazienda nos impide verificar el alcance de la solución propuesta por Orígenes y averiguar si virgen y manceba eran intercambiables. Todo parece indicar que no es así, ya que en todas las ocurrencias de manceba se puede deducir que su sentido era el de "mujer joven" (y, en ocasiones, "sirvienta"), como puede verse en la descripción de Rebeca, en la que se recurre a un sinónimo y una paráfrasis de virgen (a diferencia de otras traducciones medievales, que usaban este vocablo): "La manceba fermosa mucho, poncella, e non sabía de varón" (f. 3r).

Podría interpretarse que la elección del término manceba frente a virgen no se condice con lo expuesto más arriba acerca de la búsqueda de una unidad textual a partir de la representación tipológica, ya que el foco no está puesto sobre el interés por encontrar una prefiguración de la Virgen María en la profecía de Isaías. Sin embargo, no debe perderse de vista el marco en que está inserto este problema conceptual. La inclusión de este pasaje, que aparece primero como parte del itinerario terrenal en el nivel literal y al final como parte de la selección de profecías que el autor destaca en una suerte de cierre vaticinador, responde igualmente a una motivación estructural, puesto que la noción de viaje que gobierna el ordenamiento de los episodios de La fazienda tiene una contraparte alegórica, en la que podemos reconocer la peregrinatio vitae. Por lo tanto, la elección de manceba frente a virgen no debilita la unidad estructural de La fazienda sustentada en el recurso de la tipología. Se mantiene, entonces, la idea expuesta más arriba de que la Biblia es un gran código que contiene un sentido oculto: "the mystery of salvation through Jesus Christ which could in principle be detected even in those passages that did not seem to address salvation history overtly", como expresa Franz Van Liere (2011, p. 159).

Esta conciencia de la unidad textual se ve reforzada si atendemos al hecho de que el comienzo mismo del itinerario incluye la prefiguración de la Santísima Trinidad, con lo que el carácter circular del itinerario, que comienza y termina en Hebrón, se replica en una circularidad conceptual, en la que los extremos del recorrido se tocan en pos de la reflexión doctrinal. Por lo tanto, la aparente fisura en la composición de La fazienda que señalamos más arriba es otra de sus contradicciones identitarias, que la hacen tan peculiar frente a otras traducciones de la Biblia y la distinguen de otros itinerarios. 


\section{Conclusiones}

En El gran código, Northrop Frye describe el modo en que, como lectores, incorporamos imágenes y símbolos que nos permiten comprender y decodificar los textos literarios. Frye se refiere al modo en que, generación tras generación, se transmitió la imaginación bíblica para dejar huellas cuya procedencia exacta muchas veces es difícil de determinar, pero que definieron un modo de transmisión de ideas y una configuración de las mismas que se transparentan en gran parte de la literatura. Esta perspectiva, enmarcada en un contexto histórico-cultural definido, puede servir de anclaje para el análisis del modo en que la literatura española medieval incorporó la tradición bíblica y dio forma a sus propias tradiciones. Este no es sino un punto de acceso a un terreno rico en tópicos e imágenes y a una red de alusiones que dieron forma a un universo literario.

Las primeras noticias sobre La fazienda de Ultramar la postulaban como un texto híbrido, a mitad de camino entre la Biblia romanceada y la guía de peregrinos. Un estudio pormenorizado de los fragmentos que escapan a ambas categorías muestra que, en realidad, está formado por múltiples caminos para acceder a la palabra y los hechos divinos. La incorporación de relatos apócrifos, citas litúrgicas, microrrelatos históricos y mitológicos y la representación de la geografía mediooriental nos permiten reconstruir el panorama de los debates filosófico-doctrinales del siglo XIII, así como también su marco histórico-cultural, y conocer los alcances de las prácticas de traducción en la incipiente literatura castellana y el florecimiento de las lenguas vernáculas como lenguas literarias.

Por otra parte, como pudimos observar a lo largo de estas páginas, La fazienda es un texto de sumo interés por la intrincada red de sentidos alimentada por los problemas de traducción y de construcción de sentidos. Si bien el principio ordenador de sus episodios es sin duda la geografía de Tierra Santa, encontramos evidencias del interés que despertaba la búsqueda de un sentido que trascendiera el literal. Así, hallamos la noción de viaje explorada tanto en su aspecto más evidente, asociado al desplazamiento de las tribus de Israel y a la descripción de sus emplazamientos, como en su aprovechamiento simbólico, que amplía su significado espiritual y alude a la peregrinación de la vida hacia la salvación. Es por ello que encontramos un esquema de realización figurativa que refuerza la unidad textual y la resignifica. Los fragmentos que analizamos aquí y los problemas de traducción que implican muestran cómo el autor de La fazienda contribuyó al estudio y conocimiento de este gran código, proponiendo su interpretación a la presentación de los ángeles, la Santísima Trinidad y la Virgen. Estamos, entonces, ante un texto que, a la manera de los comentarios bíblicos heredados del período patrístico, intenta abarcar esos sentidos ocultos de la Biblia y los reformula para adecuarlos al sistema cultural de su autor y su público lector. Todo ello le otorga a La fazienda de Ultramar una identidad única y nos conduce a revalorizarla como una de las primeras obras extensas en prosa escritas en lengua castellana.

\section{REFERENCIAS}

Bartelink, G. (1984). Tres vidit, unum adoravit, formule trinitaire. Revue d'Études Augustiniennes et Patristiques, 30, 24-29.

Bizzarri, H. (Ed.). (2001). Castigos del rey don Sancho IV. Madrid: Iberoamericana.

Boeren, P. C. (Ed.). (1980). Rorgo Fretellus de Nazareth et sa description de la Terre Sainte. Histoire et édition de texte. Amsterdam: North-Holland Publishing Company.

Catalán, D. (1965). La Biblia en la literatura medieval española. Hispanic Review, 33, 310-318.

Cohn, L. y Wendland, P. (Ed.) (1902). Philonis Alexandrini. Opera quae supersunt. Berlín: Georg Reimer.

Delpy, M. S., Funes, L. y Zubillaga, C. (comp.) (2009). Estudios sobre la traducción en la Edad Media. Buenos Aires: Editorial de la Facultad de Filosofía y Letras.

Enrique-Arias, A. (Dir.). (2008). Biblia Medieval. Recuperado de: http://www.bibliamedieval.es 
Francomano, E. (2011). Castilian Vernacular Bibles in Iberia, c. 1250-1500. En S. Boynton et al. (Ed.), The Practice of the Bible in the Middle Ages (pp. 315-337). Nueva York: Columbia University Press.

Frye, N. (1982). The Great Code: The Bible and Literature. Nueva York: Harcourt Brace Jovanovich.

García de la Fuente, O. (trad.). (s/f). Agustín de Hipona, Cuestiones sobre el Heptateuco (Libro IV: Cuestiones sobre los Números). Recuperado de: http://www.augustinus.it/spagnolo/questioni_ettateuco/quest_ettateuco_4_lib ro.htm

Gerli, M. (1985). La tipología bíblica y la introducción a los Milagros de Nuestra Señora. Bulletin of Hispanic Studies, 62(1), 7-14.

Gómez Redondo, F. (1998). Historia de la prosa medieval castellana (Vol. 1: La creación del discurso prosístico: El entramado cortesano). Madrid: Cátedra

Lazar, M. (Ed.) (1965). [Almerich, Arcediano de Antioquía], La fazienda de Ultra Mar: Biblia romanceada et itinéraire biblique en prose castillane du XII siècle. Salamanca: Universidad de Salamanca.

Leslau, W. (1951). Falasha Anthology. New Haven: Yale University Press.

Marti, M. (2018). Geografía e imaginario bíblico medieval. Estudio y edición de La fazienda de Ultramar (Tesis doctoral inédita). Facultad de Filosofía y Letras, Universidad de Buenos Aires, Buenos Aires.

Michelant, H. y Raynaud, G. (1882). Itinéraires a Jérusalem et Descriptions de la Terre Sainte rédigés en français aux XIe \& XIIIe siécles. Génova: Imprimerie Jules-Guillaume Fick.

Mimouni, S. C. (1995). Dormition et Assomption de Marie. Histoire des traditions anciennes. París: Beauchesne.

Ozaeta, J. M. y Madrid, T. C. (trad.). (s/f). Agustín de Hipona, Réplica a Maximino, obispo arriano. Recuperado de: h ttp://www.augustinus.it/spagnolo/contro_massimino/index2.htm

Roberts, A. y Donaldson, J. (Ed.). (1885). Orígenes, Contra Celsus. Recuperado de: http://www.earlychristianwritin gs.com/text/origen 161.html.

Shoemaker, S. (2002). Ancient Traditions of the Virgin Mary's Dormition and Assumption. Oxford: Oxford University Press.

Solalinde, A. G. (Ed.). (1930). Alfonso el Sabio, General Estoria. Primera parte. Madrid: Consejo Superior de Investigaciones Científicas / Instituto Miguel de Cervantes.

Steiner, R., Bailey, T. y Lacoste, D. (dir.). (1987-2018). Cantus: A Database for Latin Ecclesiastical Chant. Inventories of Chant Sources. Recuperado de: http://cantus.uwaterloo.ca/

Tobler, T. (Ed.). (1874). Descriptiones Terrae Sanctae. Leipzig: J. C. Hinrichs'sche Buchhandlung.

Van Liere, F. (2011). Biblical Exegesis Through the Twelfth Century. En S. Boynton et al. (Ed.), The Practice of the Bible in the Middle Ages (pp. 157-178). Nueva York: Columbia University Press.

Weil, G. (1846). The Bible, the Koran, and the Talmud. Londres: Longman, Brown, Green, and Longmans.

\section{Notas}

1 Es interesante notar que en este pasaje (tal como señala Moshé Lazar en su estudio introductorio) se conjuga la traducción del texto hebreo y del latino. En el primero, se alude a que no se le perturbaron los ojos ni la piel, mientras que en el segundo se mencionan los ojos y los dientes ("non caligavit oculus eius nec dentes illius moti sunt"). Cfr. Dt. $34: 7$.

2 Todas las citas de La fazienda de Ultramar pertenecen a mi transcripción.

3 Llamativamente, encontramos un comentario similar en un itinerario posterior a La fazienda: la Descriptio Terrae Sanctae de Johannis Poloner (1422). Allí leemos: "Intra hanc Petram et Areopolim mediat torrens Sorec et mons Abarim, ubi Moises per angelos sepultus est” (Tobler, 1874, p. 256).

4 Todas las citas de la Biblia en castellano se harán a partir del texto de la Reina Valera.

5 Este no es el único punto de contacto de La fazienda con textos apócrifos. Por ejemplo, a continuación de la muerte de Isaías, se incluye uno de los pocos comentarios acerca de las fuentes textuales, que probablemente aludan a Ascensio Isaiae 5:1: "Bien trobamos escripto en latín que Manasés fizo matar a Isaías el propheta e lo fizo soterrar con una sierra de fust, mas no es escripto en la istoria ni non lo trobamos en el ebraico" (f. 58r). El autor no da muchas más precisiones en un pasaje de similares características, encabezado por la rúbrica "O transió Sancta María”, que trata de la asunción de María 
al cielo: "Mas trobamos en otro logar que los dicípulos vieron el cuerpo de Sancta María levar a los cielos e Sancto Tomás ovo dent la correa d'ella” (f. 79r). En este caso, sin bien el relato de la asunción de María circulaba especialmente desde el florecimiento de la tradición textual del Transitus Mariae en los primeros siglos del cristianismo, la mención del lazo entregado a Santo Tomás remite a la tradición que ganó amplia difusión desde la Historia Euthymiaca, interpolada en una homilía de Juan Damasceno hacia el siglo VIII, y que se incluyó también en el Transitus de Pseudo José de Arimatea. Véase Mimouni, 1995, pp. 624-628; y Shoemaker, 2002, p. 68.

6 En su antología de relatos de los Beta Israel, Leslau aventura la hipótesis de que la historia de la muerte de Moisés haya comenzado a circular en los siglos XIV o XV, pero se desconoce la antigüedad de sus fuentes, ya sean árabes o hebreas (1951, p. 106). El autor adscribe a la hipótesis del origen árabe basándose en el carácter humorístico del final.

7 Para un análisis comparativo de las distintas traducciones hispanomedievales de la Biblia, consúltese el corpus Biblia medieval (Enrique-Arias, 2008).

8 Véase la base de datos Cantus (Steiner, Bailey y Lacoste, 1987-2018).

9 Merece una mención aparte el modo en que se alude a la encina bajo la que estaba Abraham cuando se encontró con los ángeles: "Allí delant Ebrón es mont Manbre, e ovo ý grant árbor e fue enzina. A la raíz d'aquel árbor estava Abraam. Onde diz: "Dum staret Abraam so ilicem Manbre”' (f. 1v). Aquí es importante notar que el autor utiliza el singular para

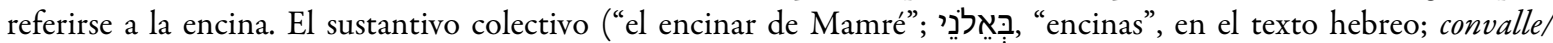
convallis, "valle", en el latino) se introdujo como una corrección destinada a evitar la idea de veneración de un árbol concreto en Mamré. Como podemos apreciar, en el responsorio del que procede esta frase también encontramos una única encina, lo que además está respaldado por el texto de la Septuaginta ( $\delta$ pui/ $\delta p \tilde{s})$.

10 Así aparece, por ejemplo, en los Castigos del rey don Sancho IV. Véase Bizzarri, 2001, p. 115.

11 La cita es prácticamente idéntica a la que encontramos en la Descriptio Terrae Sanctae de Juan de Wurzburgo. Véase Tobler, 1874, p. 177.

12 Junto a la Descriptio de Rorgo Fretellus, estos dos últimos itinerarios son algunos de los más cercanos a La fazienda de Ultramar, puesto que presentan errores conjuntivos, tales como situar Cafarnaúm en las cercanías del mar Mediterráneo (confundiéndolo con el mar de Galilea) en el caso del primero; y el emplazamiento del castillo de San Juan de Bois, en el segundo. Cabe destacar que ninguno de los itinerarios mencionados se refiere a las demás polémicas aquí analizadas.

13 De hecho, Moshé Lazar señala que la traducción y el itinerario concluyen justo antes de este punto. Si bien esta observación tiene sentido desde el punto de vista estructural, puesto que lo que antecede a este fragmento es la frase "a la vista de Manbre, o comiençan estas istorias” (f. 82v), no resulta adecuado considerar lo que sigue como un apéndice de este itinerario, ya que el propósito de las profecías es extender la noción de la peregrinatio a su contraparte simbólica, que conduce a los hombres a su redención.

14 El capítulo de Van Liere acerca de la exégesis bíblica en el siglo XII y los precedentes describe con precisión el funcionamiento de la alegorización y a la recuperación de los tipos en el Antiguo Testamento como parte de la tradición exegética más difundida en los monasterios desde Orígenes, así como también su importancia para la composición de sermones: "[the Old Testament] was thus allegorically reinterpreted in light of Christian beliefs. The images of the Old Testament story were understood to foreshadow the New Testament mysteries” (2011, pp. 161-162).

15 El pasaje, que en esta cita incluye los versículos 13-16 del capítulo antedicho, se repite casi sin modificaciones más abajo: “Afé la manceba concibrá e parrá fijo e clamará so nonbre Emanuel, ço es 'Dios con nós'. Manteca e miel conbrá por saber aborrecer el mal e escoger el bien” (f. 83r).

16 Pasaje que, sin embargo, no fue incluido en La fazienda.

17 La traducción es mía. 